\title{
DETERMINACIÓN DE LA CONTAMINACIÓN BACTERIANA EN CONOS DE GUTAPERCHA EN UNA CLÍNICA ODONTOLÓGICA DOCENTE
}

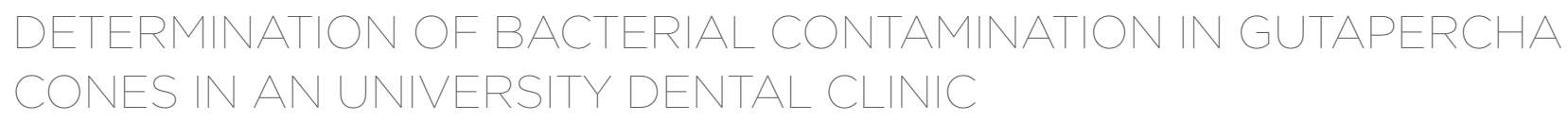

Alberto Andrés Chang-Prada ${ }^{*}$ (1)

100023805@ucientifica.edu.pe

Miguel Cabrera-Iberico ${ }^{2}$

mcabrera@ucientifica.edu.pe

\section{Carmen Rosa García-Rupaya ${ }^{2}$}

cgarciar@ucientifica.edu.pe

Artículo recibido: 21/05/2020

Arbitrado por pares

Artículo aceptado: 07/07/2020

Artículo publicado: 24/08/2020

* Autor corresponsal:

Alberto Andrés Chang-Prada

100023805@ucientifica.edu.pe

Citar como: Chang-Prada AA. CabreraIberico M, García-Rupaya C. Determinación de la contaminación bacteriana en conos de gutapercha en una clínica odontológica docente. Rev Cient Odontol (Lima). 2020; 8(2): e017.

DOI: $10.21142 / 2523-2754-0802-2020-017$

\section{RESUMEN}

Objetivo: El objetivo de este estudio fue determinar la contaminación bacteriana de los conos de gutapercha de tipo beta $(\beta)$ en los tiempos $0,24,47$ y 72 horas de las diferentes proveedurías de la Clínica Odontológica de la Universidad Científica del Sur (Lima, 2020). Materiales y métodos: Se obtuvo 16 conos de gutapercha tipo beta $(\beta)$ de empaques cerrados bajo medidas asépticas, los cuales fueron colocados en viales con $2 \mathrm{ml}$ de caldo BHI y, posteriormente, fueron sembrados en agar BHI, así como en medios selectivos agar manitol salado y agar MacConkey. Pasadas las 24 horas de incubación a $37^{\circ} \mathrm{C}$, se realizó la lectura de las placas y el conteo de UFC. El mismo procedimiento se realizó para los tiempos 24, 48 y 72 horas, lo que dio un total de 64 conos de gutapercha tipo $\beta$. Resultados: Se observó que el nivel de contaminación bacteriana fue el mismo tanto entre las distintas proveedurías como a las 0, 24, 48 y 72 horas. Solo se hallaron diferencias estadísticamente significativas $(\mathrm{p}=0,044)$ entre los distintos tiempos de la proveeduría número 5 . Finalmente, todas las muestras sometidas a la prueba de la coagulasa arrojaron resultados negativos. Conclusión: Los conos de gutapercha de tipo beta $(\beta)$ se contaminaron por igual producto de su almacenamiento y manipulación, independientemente de la proveeduría en la que permanecieron.

Palabras clave: microbiología, endodoncia, coagulasa, bacterias gramnegativas, bacterias grampositivas (DeCS)

\begin{abstract}
Objective: The purpose of this study was to determinate the bacterial contamination of Beta $(\beta)$ gutta-percha cones at 0,24, 47 and 72 hours of the different supplies of the Universidad Científica del Sur, Lima 2020. Materials and Methods: $16 \beta$-type gutta-percha cones were obtained of sealed packages under aseptic measurements, they were placed in vials with $2 \mathrm{ml} \mathrm{BHI}$ and subsequently planted in BHI agar plates as well as in selective medias as Salted mannitol agar and MacConkey agar after 24 hours of incubation at $37^{\circ}$ the plates were read and count in CFU, the same procedure was performed for the other times evaluated 24,48 and 72 hours, giving a total of $64 \beta$-type guttapercha cones. Results: It was observed that the level of bacterial contamination was the same among the different supplies in all the establish times of in this study 0, 24, 48 and 72 hours. Therefore, there were no significant differences in the level of bacterial contamination between the supplies. On the other hand, only statistically significant differences $(p=0.044)$ were found between the different times of the supply number 5. Finally, all the samples submitted to the coagulase test had a negative result. Conclusion: The gutta-percha cones of type $\beta$ were contaminated equally regardless of the supply in which they were stored or manipulated.
\end{abstract}

Keywords: Microbiology, Endodontics, Coagulase, Gram-Negative Bacteria, Gram-Positive Bacteria $(\mathrm{MeSH})$

\footnotetext{
1 Carrera de Estomatología, Universidad Científica del Sur. Lima, Perú.

2 División de Endodoncia, Carrera de Estomatología, Universidad Científica del Sur. Lima, Perú.
} 


\section{INTRODUCCIÓN}

Una de las finalidades del tratamiento endodóntico es suprimir o disminuir la presencia de microorganismos en el sistema de conductos radiculares, para salvaguardar la integridad y la salud de los tejidos contiguos $\left({ }^{1,2}\right)$. La secuencia aséptica durante todas las fases del tratamiento endodóncico es una de las principales preocupaciones del profesional. Durante la fase de obturación, se debe hacer hincapié en evitar la contaminación cruzada del conducto radicular por medio de los instrumentos o materiales de relleno. Una explicación posible para este fenómeno puede ser la introducción de conos de gutapercha de tipo beta $(\beta)$ contaminados dentro de dicho conducto $\left({ }^{2,3}\right)$.

La gutapercha es un polímero de isopreno que se obtiene del exudado de un árbol sapotáceo originario del archipiélago malayo. Los conos mencionados están compuestos por gutapercha (18\%-20\%), ceras y resinas (1\%-4\%), sulfatos metálicos (1\%-18\%) y óxido de zinc (59\%-76\%). Hasta el momento, los conos de gutapercha de tipo beta $(\beta)$ son el material de obturación más utilizado debido a sus propiedades y biocompatibilidad; sin embargo, una de sus principales desventajas es la imposibilidad de ser sometidos al proceso de esterilización convencional, debido a su característica termoplástica $\left({ }^{4}\right)$.

Existen estudios que demuestran que los conos de gutapercha tomados de empaques sellados están contaminados con diversos microorganismos; no obstante, también pueden contaminarse durante la práctica clínica, lo cual dependerá de la manipulación y los cuidados del clínico. También puede estar influenciado por los procesos de almacenamiento en las clínicas ${ }^{(5-7)}$.

En la Clínica Odontológica de la Universidad Científica del Sur se manejan diversos materiales odontológicos que son distribuidos del almacén central a diferentes espacios denominados proveedurías, las cuales tienen la función de dispensar diversos materiales a los operadores. Debido al uso constante de este material, podría producirse la contaminación de los conos de gutapercha $\left({ }^{7,8}\right)$.
Uno delos sistemas más importantes para la identificación de microorganismos es observar su crecimiento en medios de cultivo. El agar BHI se recomienda actualmente como un medio de uso general para bacteriología aerobia $\left({ }^{9}\right)$. Asimismo, existen medios de cultivo selectivos para cada tipo bacteriano. Por ejemplo, el agar manitol salado es recomendado para diferenciar estafilococos positivos y negativos a la coagulasa. Los estafilococos positivos producen colonias de color amarillo y un medio circundante del mismo color, mientras que los estafilococos negativos producen colonias de color rojo y no cambian el medio circundante $\left({ }^{10}\right)$. Otro de los medios selectivos es el agar MacConkey, que permite el aislamiento y diferenciación de enterobacterias y otros bacilos gramnegativos $\left.{ }^{(11-13}\right)$.

En el estudio de Yépez $\left({ }^{4}\right)$ se evaluó la presencia de contaminación microbiana en conos de gutapercha provenientes de empaques sellados. Se observó que el $7,1 \%$ de los conos de gutapercha estaban contaminados. Además, el 16,67\% de las bacterias halladas eran gramnegativas. A partir de esto, concluyó que los conos de gutapercha de empaques sellados no estaban estériles, por lo que sugirió su correcta desinfección.

Por otro lado, Kayaoglu et al. $\left({ }^{8}\right)$ evaluaron el grado de contaminación microbiana en empaques de conos de gutapercha sellados, antes y durante su uso en un entorno clínico. Encontraron que los conos de gutapercha tomados directamente de los empaques sellados bajo condiciones asépticas presentaban contaminación microbiana. Además, que a mayor manipulación de los empaques mayor era el grado de contaminación.

Por último, en el estudio de Pardo y Rodríguez $\left({ }^{7}\right)$ se evaluó la contaminación microbiana de los conos de gutapercha durante el uso clínico. Se encontró que el 25\% del total de los conos presentaba crecimiento microbiano. En conclusión, una inadecuada manipulación o almacenamiento influyen en el grado de contaminación microbiana de los conos de gutapercha.

El propósito de este estudio fue determinar la contaminación bacteriana de los conos de gutapercha de 
tipo beta $(\beta)$ en los tiempos $0,24,47$ y 72 horas de las diferentes proveedurías de la Clínica Odontológica de la Universidad Científica del Sur (Lima, 2020).

\section{MATERIALES Y MÉTODOS}

Este estudio fue de tipo observacional, descriptivo, transversaly prospectivo. La población estuvo conformada por todos los conos de gutapercha de tipo beta $(\beta)$ de la primera serie del stock de las proveedurías de la Clínica Odontológica de la Universidad Científica del Sur, en el periodo de enero a febrero del 2020. Asimismo, se determinó el tamaño de la muestra usando la fórmula de comparación de medias, con un poder estadístico del $80 \%$ y un nivel de confianza del $95 \%$. La muestra fue de 4 conos (\#25, \#30, \#35, \#40) por proveeduría, así como por tiempo de toma de muestra, lo que dio un total de $\mathrm{n}=64$ conos de gutapercha de tipo $\beta$.

\section{CRITERIOS DE INCLUSIÓN}

Conos de gutapercha de tipo beta $(\beta)$ del número 25 al 40 del stock proveniente de las diferentes proveedurías de la Clínica Odontológica de la Universidad Científica del Sur.

\section{CRITERIOS DE EXCLUSIÓN}

- Conos de gutapercha vencidos o dañados en su estructura.

- Conos de gutapercha que no hayan estado debidamente empacados.

- Conos de gutapercha de un lote distinto al usado para el estudio desde el inicio.

\section{RECOLECCIÓN DE LA MUESTRA}

El presente estudio se llevó a cabo en las instalaciones de la Universidad Científica del Sur. Las muestras fueron tomadas en las proveedurías de la Clínica Odontológica y el análisis se realizó en el Laboratorio de Microbiología.
Se recolectaron conos de gutapercha (Meta) de la primera serie del n. 25 al 40 del sistema manual de las proveedurías 2, 3, 5 y 6 . La primera muestra fue tomada al azar inmediatamente después de abrir el empaque en cada proveeduría, con un total de 16 conos en el día inicial. Luego, se tomó una segunda muestra a las primeras 24 horas de abiertos los empaques. Se realizó el mismo procedimiento para la tercera toma a las 48 horas y, para la cuarta toma, a las 72 horas, y se obtuvo 16 conos por cada tiempo, lo que dio un total de 64 conos. En cada muestra se verificó el número de lote a fin de evitar la inclusión de un cono de gutapercha de un lote distinto al usado para el estudio.

\section{EVALUACIÓN DE LA CONTAMINACIÓN Y CRECIMIENTO DE LAS CEPAS BACTERIANAS PRESENTES}

Los dispensadores de conos de gutapercha se cogieron y abrieron haciendo uso de guantes de látex convencionales (Cranberry, EE.UU.). Posteriormente, fueron cambiados por guantes estériles (Quimedic, Perú) para manipular las pinzas esterilizadas mediante autoclave, y con ayuda de estas se procedió a recolectar los conos de gutapercha (Meta). Estos fueron tomados directamente de sus dispensadores en las distintas proveedurías durante los tiempos establecidos. A continuación, fueron depositados en viales de $2 \mathrm{ml}$ estériles con caldo BHI (sustancia de transporte) de manera individual e, inmediatamente, se sellaron y codificaron por medio de una banda adhesiva de acuerdo con el número de cono, el tiempo de muestra y la proveeduría de procedencia. En un lapso de 2 horas, fueron trasladados, mediante un transportador de tubos de ensayo hermético, desde la Clínica Odontológica de la Universidad Científica del Sur, ubicada en el distrito de Miraflores (Lima), hasta el laboratorio de Microbiología de la Universidad Científica del Sur, en el distrito de Villa El Salvador (Lima).

Posteriormente, los viales fueron tomados con guantes y llevados al agitador Vortex. A continuación, mediante una micropipeta de $100 \mu \mathrm{l}$ y empleando tips estériles se tomó $100 \mu \mathrm{l}$ de cada vial para luego sembrarlo por inmersión sobre la superficie total de placas de agar BHI (Merck, EE. UU.). Para ello, se extendió suavemente con 
la ayuda de una espátula Drigalsky sobre la totalidad de la placa. Todo el procedimiento de siembra se realizó con el mechero de Bunsen encendido. Cada placa fue codificada con una banda adhesiva según el número de cono, el tiempo de muestra y la proveeduría de procedencia. De igual manera, se repitió el procedimiento descrito en los medios selectivos: agar manitol salado (Merck, EE. UU.), orientado al aislamiento de estafilococo, y agar Mac Conkey (Merck, EE. UU.), utilizado para el aislamiento de enterobacterias. Luego, se incubó a $37^{\circ} \mathrm{C}$, durante 24 horas, en una estufa de cultivo (Shellab, EE. UU.).

Transcurrido el tiempo exacto, se llevó a cabo el análisis bacteriológico de cada placa. Para ello, se efectuó la lectura, interpretación y recuento del crecimiento bacteriano (UFC) en cada placa del medio de cultivo respectivo. Asimismo, se aplicó la tinción de Gram a todas las placas que presentaron crecimiento bacteriano. Por último, de las placas que viraron el medio agar manitol salado (Merck, EE. UU.) se cargó un poco de la colonia bacteriana con un asa recta y haciendo uso de guantes estériles (Quimedic, Perú), y se disolvió en el plasma cuidadosamente. A continuación, se incubó a $37{ }^{\circ} \mathrm{C}$ durante 4 horas. Trascurrido este tiempo, se realizó la interpretación de la prueba de la coagulasa.

Los tiempos exactos de la toma de muestras y de su lectura, así como la hora inicial y final de incubación, código de la muestra, proveeduría de proveniencia y número de cono de gutapercha fueron registrados en una tabla de recolección de datos.

\section{PROCESAMIENTO Y ANÁLISIS DE DATOS}

Se realizó una evaluación descriptiva de las principal variable de interés: la contaminación bacteriana evaluada mediante UFC.

Para el análisis estadístico, se utilizó el software estadístico SPSS Ver.25 para Windows (IBM SPSS, Chicago, Illinois, EE. UU.). La normalidad de los datos de contaminación bacteriana, según proveedurías, se evaluó mediante la prueba de Shapiro-Wilk y, debido a que los datos no cumplieron con el principio de normalidad, se usó la prueba de Kruskal-Wallis para muestras independientes.

Por otro lado, para comparar la contaminación bacteriana según los tiempos de recolección de muestra, se evaluó la normalidad de los datos usando la prueba de Shapiro-Wilk y, debido a que los datos no cumplieron con el principio de normalidad, se empleó la prueba de Friedman. Se trabajó con un valor de $\mathrm{p}<0,05$.

\section{ASPECTOS ÉTICOS}

Este estudio fue evaluado y aprobado por el comité institucional de ética e investigación de la UCSUR, con el código de registro 261-2019-PRE8.

\section{RESULTADOS}

Se realizó una evaluación descriptiva de la contaminación bacteriana evaluada mediante UFC, y se describió la media, la desviación estándar, la mediana, el máximo y el mínimo (tabla 1). Se observó que, en todas las proveedurías, a excepción de la número 6 , la mediana tuvo valores más altos de contaminación bacteriana con el paso del tiempo. Lo mismo ocurrió con el valor máximo, mientras que, por el contrario, el valor mínimo se mantuvo en 0 en la mayoría de los casos (tabla 1 ).

Para comparar el nivel de contaminación bacteriana de los conos de gutapercha de los distintos tiempos de recolección de muestra y de cada proveeduría, se evaluó la normalidad de los datos usando la prueba de ShapiroWilk. Debido a que los datos no cumplieron con el principio de normalidad, se usó la prueba de Friedman y solo se halló diferencias estadísticamente significativas ( $p=0,044)$ entre los distintos tiempos de la proveeduría 5 (tabla 2).

Además, para comparar el nivel de contaminación bacteriana de los conos de gutapercha de las diferentes proveedurías y tiempos de recolección de muestra, se evaluó la normalidad de los datos usando la prueba de Shapiro-Wilk. Debido a que los datos no cumplieron con el principio de normalidad, se usó la prueba de Kruskal- 
Tabla 1. Análisis descriptivo de la variable contaminación bacteriana

\begin{tabular}{|c|c|c|c|c|c|c|}
\hline Proveduría & Tiempo & $x$ & DS & Me & Mín. & Máx. \\
\hline \multirow{4}{*}{2} & $\mathrm{Oh}$ & 2.5 & 5 & 0 & 0 & 10 \\
\hline & $24 \mathrm{~h}$ & 2.5 & 5 & 0 & 0 & 10 \\
\hline & $48 \mathrm{~h}$ & 1282,5 & 2479 & 65 & 0 & 5000 \\
\hline & $72 \mathrm{~h}$ & 7500 & 5000 & 10000 & 0 & 10000 \\
\hline \multirow{4}{*}{3} & $\mathrm{Oh}$ & 17,5 & 35 & 0 & 0 & 70 \\
\hline & $24 \mathrm{~h}$ & 5 & 5,77 & 5 & 0 & 10 \\
\hline & $48 \mathrm{~h}$ & 2505 & $4,996.6$ & 10 & 0 & 10000 \\
\hline & $72 \mathrm{~h}$ & 5005 & 5767,7 & 5005 & 10 & 10000 \\
\hline \multirow{4}{*}{5} & $\mathrm{Oh}$ & 2,5 & 5 & 0 & 0 & 10 \\
\hline & $24 \mathrm{~h}$ & 2,5 & 5 & 0 & 0 & 10 \\
\hline & $48 \mathrm{~h}$ & 2655 & 4904,5 & 310 & 0 & 10000 \\
\hline & $72 \mathrm{~h}$ & 2790 & 4836 & 580 & 0 & 10000 \\
\hline \multirow{4}{*}{6} & $\mathrm{Oh}$ & 10 & 8,16 & 10 & 0 & 20 \\
\hline & $24 \mathrm{~h}$ & 10 & 8,16 & 10 & 0 & 20 \\
\hline & $48 \mathrm{~h}$ & 7.5 & 5 & 10 & 0 & 10 \\
\hline & $72 \mathrm{~h}$ & 0 & 0 & 0 & 0 & 0 \\
\hline
\end{tabular}

X: Media, DS: Desviación Estándar, Me: Mediana, Mín.: Mínimo, Máx.: Máximo Valores expresados en UFC/ML (unidades formadoras de colonias sobre mililitros)

Tabla 2. Comparación de la contaminación bacteriana según tiempos de observación en cada proveeduría

\begin{tabular}{cccccc}
\hline Proveduría & Tiempo & Me & Mín. & Máx. & P \\
& $0 \mathrm{~h}$ & 0 & 0 & 10 & 0,087 \\
2 & $24 \mathrm{~h}$ & 0 & 0 & 10 & \\
& $48 \mathrm{~h}$ & 65 & 0 & 5000 & \\
& $72 \mathrm{~h}$ & 10000 & 0 & 10000 & \\
\multirow{2}{*}{3} & $0 \mathrm{~h}$ & 0 & 0 & 70 & 0,297 \\
& $24 \mathrm{~h}$ & 5 & 0 & 10 & \\
& $48 \mathrm{~h}$ & 10 & 0 & 10000 & \\
& $72 \mathrm{~h}$ & 5005 & 10 & 10000 & \\
& $0 \mathrm{~h}$ & 0 & 0 & 10 & 0,044 \\
& $24 \mathrm{~h}$ & 0 & 0 & 10 & \\
& $48 \mathrm{~h}$ & 310 & 0 & 10000 & \\
& $72 \mathrm{~h}$ & 580 & 0 & 10000 & \\
& $0 \mathrm{~h}$ & 10 & 0 & 20 & 0,117 \\
& $24 \mathrm{~h}$ & 10 & 0 & 20 & \\
& $48 \mathrm{~h}$ & 10 & 0 & 10 & \\
& $72 \mathrm{~h}$ & 0 & 0 & 0 & \\
\hline
\end{tabular}

Me: mediana, Mín.: mínimo, Máx.: máximo, P: significancia

Valores expresados en UFC/ML (unidades formadoras de colonias sobre mililitros) Prueba estadística: Prueba de Friedman.
Wallis para muestras independientes y se observó que la contaminación bacteriana fue la misma tanto entre las distintas proveedurías como a las 0, 24, 48 y 72 horas. Es decir, no hubo diferencias significativas en el nivel de contaminación bacteriana entre las proveedurías (tabla 3).

En cuanto a la tinción de Gram, se halló que el 20,59\% de las bacterias fueron gramnegativas, mientras que el $79,41 \%$ fueron grampositivas (tabla 4 ).

Por último, en el caso del crecimiento bacteriano en los medios de cultivo selectivos utilizados para este estudio, se observó la ausencia de crecimiento bacteriano en el agar Mac Conkey; sin embargo, en el agar manitol salado, solo el $25 \%(n=16)$ del total de placas $(\mathrm{n}=64)$ presentó crecimiento bacteriano. De estas últimas, únicamente el 31,25\% ( $\mathrm{n}=5)$ viró el medio (tabla 5) y, cuando fueron sometidas a la prueba de la coagulasa, todas dieron negativo.

Tabla 3. Comparación de la contaminación bacteriana entre proveedurías en cada tiempo de observación

\begin{tabular}{cccl}
\hline Tiempo & Provedurías & $\mathbf{P}$ & Interpretación \\
\hline $24 \mathrm{~h}$ & $2,3,5,6$ & 0,351 & No Significativo \\
\hline $48 \mathrm{~h}$ & $2,3,5,6$ & 0,689 & No Significativo \\
\hline $72 \mathrm{~h}$ & $2,3,5,6$ & 0,660 & No Significativo \\
\hline
\end{tabular}

P: significancia

Prueba estadística: Kruskal Wallis para muestras independientes.

Tabla 4. Descripción de la tinción Gram

\begin{tabular}{ccc}
\hline Tiempo Gram & Frecuencia & $\%$ \\
\hline Gramnegativo & 7 & $20,59 \%$ \\
\hline Grampositivo & 27 & $79,41 \%$ \\
\hline Total general & 34 & $100 \%$ \\
\hline
\end{tabular}

\%: Porcentaje.

* Cálculo con base en placas que presentaron contaminación bacteriana.

Tabla 5. Descripción de conversión del agar manitol salado

\begin{tabular}{ccc|}
\hline Respuesta al AMS & Frecuencia & $\%$ \\
\hline Positivo & 5 & $31,25 \%$ \\
\hline Negativo & 11 & $68,75 \%$ \\
\hline Total general & 16 & $100 \%$ \\
\hline
\end{tabular}

\%: porcentaje, AMS: agar manitol salado

* Cálculo con base en placas que presentaron contaminación bacteriana en AMS 


\section{DISCUSIÓN}

El principal objetivo de este estudio fue evidenciar si los conos de gutapercha utilizados en las proveedurías de la Clínica Odontológica de la Universidad Científica del Sur presentaban contaminación bacteriana como consecuencia de su almacenamiento o su manipulación. Esto se justifica debido a que no se han realizado estudios de esta naturaleza en esta clínica. Además, se trata de un factor muy importante, ya que podría vulnerar la cadena de asepsia en la terapia endodóntica $\left({ }^{14}\right)$.

En la lectura de las placas de los conos de gutapercha de tipo beta $(\beta)$ del stock de la Clínica Odontológica, a las 0 horas, se detectó un crecimiento bacteriano del 37,5\%; por ello, es posible inferir que los conos de gutapercha no están completamente estériles cuando se expenden en el mercado. Este hallazgo también se observa en el estudio de Yépez ${ }^{4}$ ), que encontró contaminación bacteriana en cajas de conos de gutapercha de la marca Meta recién abiertas bajo condiciones asépticas. Asimismo, Kayaoglu et al. $\left({ }^{8}\right)$, en su estudio, observaron contaminación bacteriana en cajas de conos recién abiertas en condiciones asépticas. Por otro lado, existen estudios como los de Quijada ( ${ }^{6}$ y Pacheco et al. $\left({ }^{12}\right)$ en los que no se encontró contaminación bacteriana inicial en las cajas de conos de gutapercha. Sin embargo, debido a que los conos podrían no venir estériles de fábrica y esto podría poner en riesgo la secuencia aséptica de la terapia endodóntica, es recomendable desinfectar el cono de gutapercha antes de ser usado $\left.{ }^{(14}\right)$.

Una vez que los dispensadores de conos de gutapercha de tipo beta $(\beta)$ fueron abiertos, permanecieron en las distintas proveedurías de la Clínica Odontológica de la Universidad Científica del Sur y fueron usados de manera regular por los operadores. Conforme pasaron las horas, se pudo observar en las cajas abiertas un mayor nivel de contaminación bacteriana. La respuesta a este fenómeno puede estar en lo hallado en el trabajo de Ozalp et al. $\left({ }^{1}\right)$, el cual demostró que, debido a la exposición de los conos de gutapercha al entorno clínico, estos pueden contaminarse en su totalidad por diversos microorganismos. De igual forma, el estudio de Pang et al. ${ }^{15}$ ) mostró que el 19,4\% de los conos de gutapercha expuestos a un medio clínico estaban contaminados. Lo anterior reafirma la importancia que tiene el correcto almacenamiento de los conos de gutapercha.

De igual manera, el aumento de la contaminación bacteriana podría deberse a la manipulación de los conos de gutapercha por parte de los operadores. Kayaoglu et al. $\left(^{8}\right)$ sostienen que el modo de uso de los conos está asociado con el riesgo de contaminación, pues en su estudio se encontró contaminación en la mayoría de las cajas de conos de gutapercha manipuladas. Un hecho similar se registró en los estudios de Pang et al. ${ }^{15}$ ) y Silva et al. $\left({ }^{16}\right)$.

Por el contrario, el estudio de Quijada ( $\left.{ }^{6}\right)$ no encontró un aumento en la contaminación bacteriana de los conos de gutapercha manipulados por los operadores; además, señala que la explicación a este fenómeno radica en la presencia del óxido de zinc en la composición de los conos, sustancia a la cual se le reconocen propiedades antibacterianas $\left({ }^{17}\right)$.

En algunas de las muestras de este estudio, se encontró contaminación a las 0 y 24 horas de abiertas las cajas. Lo mismo sucedió en las horas posteriores de recolección. Sin embargo, en otras muestras hay una reducción del nivel de contaminación bacteriana pasadas las 24 horas, hecho que también se observa en el estudio de Kayaoglu et al. $\left.{ }^{8}\right)$, quienes señalan que esto podría deberse a que la contaminación bacteriana no afecta el contenido completo de la caja de manera uniforme. Por ende, es posible que mientras algunos de los conos de gutapercha en el paquete se contaminaron durante el uso clínico, otros hayan permanecido libres de contaminación.

Por otra parte, solo se halló diferencias estadísticamente significativas entre los distintos tiempos de la proveeduría 5. Una de las posibles causas estaría relacionada con la constante manipulación del material, ya que es esta la proveeduría que abastece al ambiente denominado clínica 5, donde se realizan la mayor parte de tratamientos endodónticos.

En cuanto al crecimiento bacteriano en los medios selectivos utilizados para este estudio, se observó ausencia de crecimiento bacteriano en el agar Mac Conkey, medio específico para el aislamiento y diferenciación 
de enterobacterias, resultado similar al encontrado en el estudio de Jiménez et al. $\left({ }^{14}\right)$. Por el contrario, en el medio selectivo agar manitol salado, orientado al aislamiento y diferenciación de estafilococos, se halló un crecimiento bacteriano del $25 \%$, resultado similar al del estudio de Quijada $\left(^{6}\right)$.

Para descartar la patogenicidad de aquellas colonias que viraron el medio agar manitol salado, se les aplicó la prueba de la coagulasa, a la que todos dieron negativo, por lo que se descarta la presencia de estafilococos patógenos como el S. aureus $\left({ }^{6,14}\right)$.

Este estudio ha permitido identificar que sí puede existir un alto nivel de contaminación bacteriana en los conos de gutapercha que se expenden normalmente a través de las proveedurías. Por ello, se sugiere desinfectarlos antes de que sean empleados en el acto endodóntico mediante la sumersión en agentes químicos como el hipoclorito de sodio al $1 \%$, durante 5 minutos, o la clorhexidina al $2 \%$, por 1 minuto. Asimismo, se pueden usar otros agentes químicos como polivinilpirrolidona-yodo al $10 \%$, peróxido de hidrógeno al 6\% o glutaraldehído al $2 \%\left({ }^{18-20}\right)$.

Además, se debe motivar tanto a los operadores como al personal auxiliar a capacitarse correctamente en el traslado, manipulación y almacenamiento del material. Finalmente, sería recomendable realizar estudios posteriores para determinar si el nivel de contaminación bacteriana disminuye como consecuencia de la capacitación sugerida.

\section{CONCLUSIONES}

Los conos de gutapercha del stock adquirido por la Clínica Odontológica de la Universidad Científica del Sur y que fueron usados en este estudio no se encontraban estériles en su totalidad. Asimismo, se observó que los conos de gutapercha resultan contaminados como producto de su almacenamiento y manipulación. Además, la contaminación bacteriana aumentó con el tiempo de almacenamiento y manipulación.
No se hallaron diferencias significativas entre las proveedurías, es decir, los conos de gutapercha se contaminaron por igual independientemente de la proveeduría en la que fueron almacenados o manipulados.

Contribución de autoría: Alberto Chang Prada estuvo encargado de la concepción, la recolección de información, el análisis y la interpretación de datos, la revisión crítica del manuscrito y la aprobación de su versión final. Miguel Cabrera Iberico y Carmen García Rupaya participaron en el análisis e interpretación de datos, la revisión crítica del manuscrito y la aprobación de su versión final.

Fuente de financiamiento: Autofinanciado.

Potenciales conflictos de intereses: Los autores declaran no tener conflictos de intereses de ningún tipo. 


\section{REFERENCIAS BIBLIOGRÁFICAS}

1. Ozalp N, Okte Z, Ozcelik B. The rapid sterilization of guttapercha cones with sodium hypochlorite and glutaraldehyde. J Endod. 2006; 32 (12): 1202-4. doi: 10.1016/j.joen.2006.08.009

2. Canalda C, Brau E. Endodoncia técnicas clínicas y bases científicas. 3. ${ }^{\mathrm{a}}$ ed. Barcelona: Elsevier; 2014.

3. Castelluci A. Endodontics. Vol. 2. 2. ${ }^{\mathrm{a}}$ ed. Florencia: Il Tridente; 2005.

4. Yépez JE. Evaluación del grado de contaminación microbiana de conos de gutapercha presentes en empaques totalmente sellados por el fabricante [Tesis]. Quito: Universidad San Francisco de Quito, Colegio de Ciencias de la Salud; 2012.

5. Rôças I, et al. Association of Enterococcus faecalis with different forms of periradicular diseases. J Endod. 2004; 30 (5): 315-20. doi: 10.1097/00004770-200405000-00004.

6. Quijada L. Contaminación bacteriana de los conos de gutapercha como resultado de su almacenamiento y manipulación. [Tesis]. Talca: Universidad de Talca, Escuela de Odontología; 2002.

7. Pardo D, Rodríguez C. Evaluación in vitro de la contaminación microbiana de conos de gutapercha en uso clínico en Bucaramanga y su área metropolitana. [Tesis]. Bucaramanga: Universidad Santo Tomás, Postgrado de Endodoncia; 2015.

8. Kayaoglu G, et al. Examination of gutta-percha cones for microbial contamination during chemical use. J Appl Oral Sci. 2009; 17 (3): 244-7. doi: 10.1590/s1678-77572009000300022

9. Flores M, Welch D. Clinical microbiology procedures handbook. Vol. 1. Washington D. C.: Isenberg; 1992.

10. Chapman GH. The significance of sodium chloride in studies of Staphylococci. J Bacteriol. 1945; 50 (2): 201-3.

11. Baron E, Peterson L, Finegold S. Bailey \& Scott's diagnostic microbiology. 9.a ed. St. Louis, Misuri: Mosby; 1994.
12. Pacheco M, Platero R. Condición microbiológica de conos de gutapercha de diferentes marcas comerciales distribuidas en san salvador. [Tesis]. San Salvador: Universidad de E1 Salvador, Facultad de Odontología; 2009.

13. Murray P, Rosenthal K, Pfauer M. Microbiología médica. 6.a ed. Madrid: Elsevier; 2009.

14. Jiménez K, Cortés C, Rojas N, Zeledón R, Montero M. Eficiencia de diferentes protocolos de desinfección de conos de gutapercha con $\mathrm{NaClO}$, ante las especies $S$. aureus y E. faecalis. Rev. Cient. Odontol. 2014; 10 (1): 37-41.

15. Pang N, Jung I, Bae K, Baek S, Lee W, Kum K. Effects of shortterm chemical disinfection of gutta-percha cones: identification of affected microbes and alterations in surface texture and physical properties. J Endod. 2007; 33 (5): 594-8. doi: 10.1016/j. joen.2007.01.019

16. Da Silva E, Sponchiado E, Franco A. Microbiological assessment of contamination of gutta-percha cones used by post-graduation students. J Health Sci Inst. 2010; 28 (3): 235-6.

17. Moorer W, Genet J. Antibacterial activity of gutta-percha cones attributed to the zinc oxide component. Oral Surg Oral Med Oral Pathol. 1982; 53 (5): 507-17.

18. Da Motta P, de Figueiredo C, Maltos S, Nicoli J, Ribeiro A, Maltos K, et al. Efficacy of chemical sterilization and storage conditions of gutta-percha cones. Int Endod J. 2001; 34 (1): 4359. doi: 10.1046/j.1365-2591.2001.00412.x

19. Cardoso C, Redmerski R, Bittencourt N, Kotaka C. Effectiveness of different chemical agents in rapid decontamination of guttapercha cones. Braz. J. Microbiol. 2000; 31 (1): 67-71.

20. Cardoso C, Kotaka C, Redmerski R, Guilhermetti M, Queiroz A. Rapid decontamination of gutta-percha cones with sodium hypochlorite. J Endod 1999; 25: 498-501. doi: 10.1016/S00992399(99)80290-8 